\title{
Researching Identity and Interculturality
}

\author{
Lønsmann, Dorte
}

Document Version

Accepted author manuscript

Published in:

E L T Journal

DOI:

10.1093/elt/ccv059

Publication date:

2016

License

Unspecified

Citation for published version (APA):

Lønsmann, D. (2016). Researching Identity and Interculturality. E L T Journal, 70(1), 116-118.

https://doi.org/10.1093/elt/ccv059

Link to publication in CBS Research Portal

\section{General rights}

Copyright and moral rights for the publications made accessible in the public portal are retained by the authors and/or other copyright owners and it is a condition of accessing publications that users recognise and abide by the legal requirements associated with these rights.

Take down policy

If you believe that this document breaches copyright please contact us (research.lib@cbs.dk) providing details, and we will remove access to the work immediately and investigate your claim.

Download date: 26. Apr. 2023 


\section{Researching Identity and Interculturality \\ Dorte Lonsmann}

Book review (Post print version)

This is a pre-copyedited, author-produced PDF of an article accepted for publication in EL T Journa/following peer review. The version of record ELT J (2016) 70 (1): 116118, first published online 9 October 2015, is available at 001: 10.1093/elt/ccv059

Uploaded to Research@CBS: Januar २०16 


\section{Researching Identity and Interculturality. Fred Dervin and Karen Risager (eds). Routledge 2015, 245 pp., \$135.00 (hardback) ISBN 978-0-415-73912-2}

When I started as a researcher interested in language, culture and identity, it quickly became clear that all three concepts have so many different definitions and can be approached from so many theoretical perspectives and through so many different methods, that one of the first things a beginning researcher needs to do is construct her own position in this jungle. Only then can the real work begin. But it is a jungle out there, and that is why Researching Identity and Interculturality is a welcome addition to the methodology literature in the field of applied linguistics.

As a whole, the book has a clear and well-articulated anti-essentialist theoretical framework. In the Introduction Risager and Dervin position the volume clearly within a social constructionist perspective that regards identity and interculturality as continually constructed and negotiated in interaction. From this perspective, culture is seen as something we do, not something we have. Risager and Dervin discuss how research on identity has moved from notions of primordialism, essentialism and perennialism to instrumentalism, situationalism and modernism. This shift in focus also entails a change of research question: from "what is somebody's identity?" to " how do people construct their identities?" (8). In this perspective, discourse is a central concept, and the study of discourse a key method of investigating interculturality. However, despite the common anti-essentialist framework, the ten chapters introduce the reader to ten different ways of studying identity and interculturality. As such the book manages to take a firm theoretical standpoint, while at the same time presenting a range of possible methodological avenues for researchers to explore.

In the Introduction, Risager and Dervin also position the book within the field of applied linguistics, but emphasise its cross-disciplinary perspective with the inclusion of theories and methodologies from fields such as anthropology, cultural sociology, postcolonial studies and social psychology. The book deals with research methodology within the fields of identity and interculturality, and intercultural in this book has a wide definition. Rather than referring to the meeting between people of different national or ethnic cultures, interculturality is here used (also) to refer to the meeting between researcher and research participants, between different generations of the same family, or between different cultural identities performed in interactions such as those of student and student counsellor.

The anthology consists of four sections with a total of ten chapters plus an Introduction and Concluding Remarks by the two editors. Section 1 focuses on the use of narrative analysis to study identity. In Chapter 1 Kadianaki, O'Sullivan-Lago \& Gillespie propose 'dialogical analysis' as a framework for studying narratives. They focus on 'semantic encounters', i.e. places in discourse where participants deal with other voices positioning them. Showing how dialogical analysis can be used to highlight tensions between the different voices an individual has access to, but also how these tensions can be used to resist, embrace and transform identities, the chapter is an interesting introduction to dialogical analysis. Keeping the focus on identities in narratives, De Fina's chapter illustrates how to combine analysis of "locally relevant discourse phenomena" (46) with attention to macro issues of power and access to linguistic resources. De Fina's 
chapter is a well-written depiction of how narrative analysis can shed light on the way that interactants draw not just on established stereotypes, i.e. 'enregistered identities', but also on 'emergent identities' in their positioning of themselves and others in discourses about language and migration. Concluding Section 1 is Baynham's chapter on 'brought along' and 'brought about' identities. In a lengthy theoretical discussion with reference to Hall, Butler, Althusser, Bourdieu and Foucault, Baynham focuses on the tensions between the 'brought along' and 'brought about' dimensions of identity. While distancing himself from essentialist notions of identity, Baynham instead defines 'brought along' identities as relatively stable identity positions, built up over time through repetitions in a series of interactions. Together the three chapters in Section 1 provide the reader with a diverse toolbox helpful to researchers entering into narrative analysis.

In Section 2, the three chapters focus on analyses of natural interaction. In Chapter 4 Stokoe and Attenborough introduce readers to the use of Conversation Analysis (CA) and Membership Categorization Analysis (MCA) for the purpose of catching "phenomena such as culture and identity in flight" (90), following Stokoe (2012). Stokoe and Attenborough focus on how members invoke and produce cultural knowledge by invoking categorical practices, but also show what such categorisations can accomplish in the interaction, e.g. task distribution or showing affiliation. Stokoe and Attenborough provide the reader with an easy-to-follow introduction to the use of CA and MCA and explicate not just how to analyse identities, but also how identity work can be used to do things in an interaction. In Chapter 5 Zhu offers another take on MCA, drawing on the concept of the Membership Categorization Device. Zhu's analysis focuses on 'translanguaging practices', specifically how a multilingual Chinese diaspora family make use of interactional resources to 'do' cultural identities related to Chineseness. Zhu's chapter shows how the interculturality perspective can be fruitfully applied also to contexts where participants are perceived to be from the same cultural group, but from different generations. Tranekjær's Chapter 6 is a plea for the use of discursive ethnography, a method of microanalysis which combines ethnomethodology with discursive psychology and cultural studies. Tranekjær focuses on the concept of 'passing', defined as "a cultural performance of a particular membership that is either accepted or denied by others" (131). Similarly to Section 1, Section 2 provides the reader with three distinct approaches within the same broad framework, here ethnomethodology. Rather than seeming repetitive, the three chapters complement each other in their focus on 'categorical practices', 'translanguaging' and 'passing' respectively.

Section 3 includes two chapters, both with an ethnographic focus. In Chapter 7 Galal shows that focusing on how the ethnographer constructs her object, and incorporating participants' responses to this construction produces valuable knowledge about the research object. With its particular focus on researcher-participant interaction, Galal's account belongs to the field of reflexive ethnography to which it is a welcome addition with its investigation of how categories are constructed, contested, silenced and reclaimed in ethnographic encounters. Like Galal, Bojsen focuses in Chapter 8 on the communication process between researcher and participants. While her reflections on the position and categorisation of research participants are very useful, most of Bojsen's chapter reads like it is written for insiders into the field of critical research into development work in Africa. As part of a book on research methodology, the chapter could have benefitted from an attempt to broaden the perspective to studies of identity and interculturality more generally.

Section 4 presents the last two chapters of the book. In Chapter 9 Frello introduces an 'analytics of hybridity'. She suggests that researchers should focus on how blendings are constructed as legitimate or 
not in discourses on identity and belonging, e.g. by focusing on the dichotomy 'purity/hybridity' as a discursive resource. Frello's discussion of different 'transgression concepts' such as interculturality, transculturality, diaspora and hybridity (Ang 2001, Friedman 1999, Hall 1991, Hall 1996) shows her overview of the field and allows her to position her own ideas in relation to existing research. Frello's chapter is a refreshing argument for taking a meta perspective on hybridity, i.e. studying the reception of different kinds of hybridity as legitimate or illegitimate. In the final chapter of the volume, Kramsch deals with the distinction between identity and subjectivity, and between modernist and postmodernist research into identity and interculturality. Similarly to Galal's chapter, Kramsch focuses on researcher reflexivity and sheds light on the reflexivity inherent in postmodernist analysis.

The perspective on identity as constructed in interaction features prominently in all chapters of Researching Identity and Interculturality. From Tranekjær's perspective on cultural identity as "momentary identifications with particular subject positions" (125) to Kramsch's plea for making a distinction between modernist notions of identity and postmodernist notions of subjectivity, the authors position themselves firmly within the branch of identity studies that focuses on how people construct their identities rather than on what somebody's identity is. As such the book is well-suited for students and early-career scholars looking to familiarize themselves with the social constructionist perspective on identity and interculturality, and at the same time gain knowledge of a wide range of different methodologies that can be used to study these topics.

Two other themes taken up in the volume add important layers to the discussion of research methodology in applied linguistics. In the Introduction Dervin and Risager emphasise the co-constructed nature of research interactions and stress the importance of reflexivity especially when researching 'the Other'. This theme of researcher reflexivity is picked up in several of the chapters (particularly in Kramsch's discussion of researcher subject positions, and in Galal and Bojsen's attention to the terminology used to describe research participants). While the volume does not focus specifically on English language teaching, it does thematise research in multilingual settings. Dervin and Risager draw attention to the methodological complexities of researching multilingual settings, including the use of interpreters and translators and the role of language choice and language ideologies in the research process. Inspiration can be found as well as in the chapters of Zhu, De Fina and Kramsch.

In conclusion, Researching Identity and Interculturality is a well-written and well-edited volume which introduces a wide range of theoretical and methodological perspectives on the study of identity and interculturality. The individual chapters in the book engage fruitfully with each other and together with the common framework, this gives the reader the impression of a coherent work despite the many different methodologies outlined by the chapters. As such it is well-suited for students and others trying to gain an overview of methodologies for studying identity and interculturality in a social constructionist framework.

\section{References}

Ang, I. 2005. On not speaking Chinese: Living between Asia and the West. London \& New York: Routledge. Friedman, J. 1999. 'The hybridization of roots and the abhorrence of the bush' in M. Featherstone and S. Lash (eds.). Spaces of Culture: City-Nation-World. London: Sage, 230-256. 
Hall, S. 1991. 'Old and new identities, old and new ethnicities' in A. D. King (ed.). Culture, Globalization and the World-System: Contemporary Conditions for the Representation of Identity. Basingstoke: Macmillan, 4168.

Hall, S. 1996. 'When was 'the post-colonial'? Thinking at the limit' in I. Chambers and L. Curti (eds.). The post-colonial question: Common skies, divided horizons. London \& New York: Routledge, 242-260.

Stokoe, E. 2012. 'Moving forward with membership categorization analysis: Methods for systematic analysis'. Discourse Studies 14/3: 277-303.

\section{The reviewer}

Dorte Lønsmann is Assistant Professor at the Department of International Business Communication at Copenhagen Business School, Denmark, and a member of the LINGCORP research group. Her research interests include language ideologies, language and identity, English as a global language and ethnographic research methodology. Her current research focuses on multilingual workplaces, including investigations of language policy, language practice, language ideologies and social identities.

Email: dl.ibc@cbs.dk 